Thorax (1975), 30, 285.

\title{
The pulmonary circulation in cystic fibrosis
}

\author{
D A VID R Y L A N D a d L Y N N REID \\ Department of Experimental Pathology, Cardiothoracic Institute, Brompton Hospital, \\ London $S W 3$
}

\begin{abstract}
Ryland, D. and Reid, Lynne (1975). Thorax, 30, 285-292. The pulmonary circulation in cystic fibrosis. The hearts and lungs of 36 patients dying of cystic fibrosis have been studied to establish the relationship between right ventricular hypertrophy (RVH), pathological changes in the pulmonary circulation, and the clinical features.

The presence and degree of RVH were measured by Fulton's technique of weighing the ventricles separately. Of the subjects who died after the age of 3 years, one in six had no RVH, although the mean age of this group was not significantly different from that of the remainder.

There was no correlation between duration of cyanosis, haemoglobin levels, and RVH. Although not statistically significant, the cases without RVH tended to have had clubbing of the finger-nails for longer periods before death.

The electrocardiogram was useful in the diagnosis of RVH. Right ventricular hypertrophy was common in children with lungs of large volume as judged by the radiographic centile of lung length.

Cases with RVH show reduced background haze in the arteriogram and fewer arteries per unit area of lung. For the first time thickening of the medial muscle layer proportional to the degree of RVH has been demonstrated, only in the smaller arteries. Arterial subintimal fibrosis is more common in cases with $\mathrm{RVH}$, as is thickening of the walls of small pulmonary veins.

The implications of these findings are discussed.
\end{abstract}

Since the description of cystic fibrosis (CF) by Andersen in 1938, the development of cor pulmonale and pulmonary hypertension has been recognized as an important feature in the natural history of the disease (Andersen, 1938; Wigglesworth, 1946; Andersen, 1949; May and Lowe, 1949).

Royce (1951) stated that chronic 'cor pulmonale' was to be expected in $70 \%$ of children dying of CF; a similar incidence was found by Schwachman and Kulczycki (1958). Physiological studies of the pulmonary circulation in cystic fibrosis (Goldring et al., 1964; Kelminson, Cotton, and Vogel, 1967) suggested that hypoxia was the principal stimulus to the production of pulmonary hypertension in CF and that the latter was sometimes partially reversible, although clinical assessment of pulmonary hypertension during life in CF patients can be difficult (Siassi, Moss, and Dooley, 1971).

Morphological observations on the pulmonary circulation in CF were limited until 1963 when
Bowden and Wyatt found right ventricular hypertrophy (RVH), assessed by right ventricular wall thickness, in a group of seven subjects dying of $\mathrm{CF}$; they considered that this was due to hypoxic pulmonary hypertension and the opening up of anastomoses between the pulmonary and bronchial artery systems. They did not find gross destruction of the parenchyma or of the capillary bed.

Esterly and Oppenheimer (1968) found significant parenchymal destruction in only three of 84 cases, which they thought pointed to the importance of the pulmonary vessels in the pathogenesis of RVH. Kelminson et al. (1967) reported medial hypertrophy of the pulmonary arteries in one patient dying of CF.

Davies (1969) reported detailed quantitative analysis of the pulmonary arterial circulation in four cases of CF. While only two had RVH at necropsy, all four showed an increase in the thickness of the medial muscle coat of the pulmonary arteries, and extension of muscle into 
vessels smaller than those containing muscle in the normal subject. Paradoxically the greatest increase in pulmonary artery muscle was found in one of the two cases with no RVH.

More recently, Symchych (1971) reported increased medial thickness in the pulmonary arteries of nine CF cases when compared with controls. Neither he nor Davies established any correlation between degrees of arterial wall thickening and the degree of RVH. Both authors reported the greatest changes in the smallest pulmonary arteries.

\section{PRESENT STUDY}

In this study the hearts and lungs of $36 \mathrm{CF}$ patients were studied using Davies' accurate quantitative morphometric techniques. The clinical histories, chest radiographs, electrocardiograms, and certain physical signs during life were also assessed.

It was hoped that close statistical analysis of the results in this larger group would elucidate the relationship between the development of cor pulmonale (defined by the World Health Organization Report No. 213 (1961) as right ventricular hypertrophy of pulmonary origin), its clinical course, and the changes in the vascular tree.

\section{MATERIAL AND METHODS}

In all 36 cases the heart was obtained. In 30 cases both lungs were available; in the remaining six cases only one lung. The clinical history was assessed in every case from the hospital records and consultation with the patients' physicians.

Postero-anterior chest radiographs were analysed using the centile standards for 'heart diameter' and 'lung length' prepared by Simon et al. (1972). The last chest radiograph taken before death was analysed in 24 of the cases. For the others, radiographs were either not available or were not included because the patient succumbed before the age of 6 years, below which Simon's standards are not applicable.

Electrocardiograms had been recorded in only 15 patients. These were measured to obtain the angle of the frontal axis of the main ventricular deflection recorded from the limb leads. The size of this angle has been shown (Millard, 1965) to be the most reliable evidence of the presence of RVH in adult chronic bronchitis.

\section{PATHOLOGICAL TECHNIQUES}

HEART WEIGHT The presence and degree of RVH were assessed by the method of Fulton,
Hutchinson, and Jones (1952). This depends of weighing the right ventricle (RV) separate from the left ventricle and the interventriculat septum $(\mathrm{LV}+\mathrm{S})$. In the adult, Fulton used bot the ratio of $L V+S$ to $R V$ and the absolufe weights of the right ventricle as indices of RVH. Since in the child no range of normal weights for cardiac chambers at different ages has been established, in the present study the rat $L V+S: R V$ was used, a value of less than $2: 8$ indicating RVH. In early infancy, right ventrix cular predominance is normal, the 'adult' ratio between the chambers being achieved by the thifg or fourth month of life (Recavarren and Ariaso Stella 1964; Shinebourne and Howarth, 1973d Therefore the patients were grouped according both age and heart weight.

LUNG MORPHOLOGY The methods used in the preparation and morphological analysis of the lungs have been fully described elsewhere (Elliot 1964; Davies, 1969; Davies and Reid, 1970; Hislog 1971). The arteries of one or both lungs of each case of the present group were injected with warm barium/gelatine mixture under a constagit pressure of $100 \mathrm{~cm}$ of water. In 12 cases the veis of one lung were injected by the same technique The medium penetrates to vessels of about $15 \mu$ 을 diameter. Injection under a standard hypertensive pressure ensures maximal distension of all the vessels in the lungs and permits valid compariso between cases.

Immediately after injection the lungs were im flated by running $10 \%$ formal saline solution into the main bronchus from a pressure head of $45 \mathrm{~cm}$ until the pleura was tense. No attempt was made to inflate the lungs to a particular volume, since small changes in volume would affect linear $\frac{\phi}{5}$ mensions very little.

The lung volume was measured by water de placement and allowance was made for shrinka during fixation. After fixation the lung was cat into $1 \mathrm{~cm}$ thick slices $(0.5 \mathrm{~cm}$ in the smaller lungs the relative volumes occupied by the largets structures (arteries, veins, and bronchi) and ty parenchyma were measured by a point-countimg technique (Dunnill, 1962; Hislop and Reid, 1970 Four blocks of tissue $(2 \mathrm{~cm} \times 2 \mathrm{~cm})$ were takê from each lung chosen by the stratified random selection procedure of Dunnill (1962) and Weibê. and Gomez (1962). Microscopic analysis consist of measurement of:

(1) arterial or venous density, that is, the number of vessels below $500 \mu \mathrm{m}$ diameter per $\mathrm{mm}^{2}$ of lung (corrections were made for 
shrinkage during fixation and cutting of the sections);

(2) medial muscle wall thickness of the arteries or veins in each section. This was expressed as the ratio of medial thickness measured between internal and external elastic laminae, to the external diameter of the vessel. Grouping the arteries or veins into size ranges allows wall thickness at various size levels to be calculated for each case;

(3) population counts. Elliott (1964) showed that arterial wall muscle does not end abruptly, but that the complete muscular sheath gives way to a spiral of muscle which persists more distally before the artery becomes truly non-muscular. Thus small artery walls have been classified as muscular, partially muscular or non-muscular (Fig. 1). Analysis by size and structure of all arteries in a section yields a 'population' count, enabling the percentage of partially muscular arteries present in a given size range to be assessed. This indicates accurately the penetration of muscle into small arteries. It may be noted that the diameter of the smallest muscular artery and the largest non-muscular artery necessarily refers to single vessels, while the size range at which partially muscular arteries are most common depends on a large number of vessels. Since this feature of the population count was most reliable and least subject to variation, it was used to assess peripheral extension of muscle;

(4) intimal changes. The presence of intimal thickening and of subintimal longitudinal muscle formation was noted. This change was rare (affecting fewer than $5 \%$ of vessels), and its distribution patchy, being almost always in the most damaged region

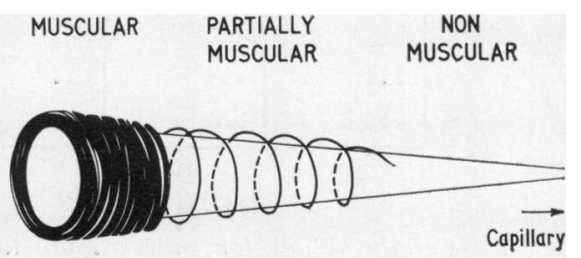

CROSS SECTION
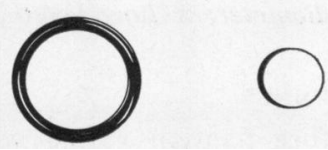

FIG. 1. Diagram showing muscle fibre distribution in small pulmonary artery wall. of lung. This made precise quantification difficult. The number of blocks of tissue in which these changes were seen was estimated for each case.

\section{RESULTS}

On the basis of heart weights the subjects were divided into five groups (Table):

T A B L E

CYSTIC FIBROSIS PATIENTS

\begin{tabular}{|c|c|c|c|c|}
\hline \multicolumn{2}{|c|}{ Group } & $\begin{array}{c}\text { Average } \\
\text { Age }\end{array}$ & Range & $\frac{L V+S}{R V}$ \\
\hline $\begin{array}{l}\mathbf{A} \\
\mathbf{B} \\
\mathbf{C} \\
\mathbf{D} \\
\mathbf{E}\end{array}$ & $\begin{array}{lr}\text { Neonate } & \text { (1) } \\
\text { Infants } & (3) \\
\text { Non-RVH } & (6) \\
\text { Mild RVH } & \text { (12) } \\
\text { Severe RVH } & \text { (14) }\end{array}$ & $\begin{array}{l}5 \text { days } \\
3.3 \mathrm{mth} \\
12 \mathrm{yr} 11 \mathrm{mth} \\
10 \mathrm{yr} 8 \mathrm{mth} \\
10 \mathrm{yr} 10 \mathrm{mth}\end{array}$ & $\begin{array}{l}- \\
3-4 \mathrm{mth} \\
5-21 \mathrm{yr} \\
4-19 \mathrm{yr} \\
3-20 \mathrm{yr}\end{array}$ & $\begin{array}{l}1.8 \\
2.8 \\
2.56 \\
1.68 \\
1.22\end{array}$ \\
\hline
\end{tabular}

A a neonate of 5 days who died of meconium ileus. The ratio $(\mathrm{LV}+\mathrm{S} / \mathrm{RV})$ of 1.8 indicates the right ventricular predominance normal at this age;

B three children dying of respiratory infections between the ages of 3 and 4 months. All had attained normal adult $(\mathrm{LV}+\mathrm{S} / \mathrm{RV})$ ratios;

C six patients between 5 and 21 years. All had the severe lung changes that frequently cause death in cystic fibrosis. Despite the long duration of their disease none had RVH.

Groups D and E included 26 patients in whom RVH was found at necropsy. These were divided into mild RVH (group D) whose $\mathrm{LV}+\mathrm{S} / \mathrm{RV}$ ratios lay between $2 \cdot 1$ and $1 \cdot 4$, and severe RVH (group E) whose ratios were below 1.4 .

Thus of the 32 children who died after the age of 1 year, six $(18 \%)$ had not developed RVH. No significant difference was found between the mean age at death for groups $\mathrm{C}, \mathrm{D}$, and $\mathrm{E}$.

\section{CLINICAL FEATURES}

HAEMOGLOBIN None of the children at any stage had haemoglobin levels in excess of $16.6 \mathrm{~g} / \mathrm{dl}$ $(110 \%)$. Unfortunately, haematocrit measurements were not usually available. In two cases serum iron levels had been measured and were in the low normal range.

CYANOSIS In the absence of any other relative data it seems justified to regard the mean duration of cyanosis in each group. Although there was wide variation between cases, somewhat longer periods of cyanosis were recorded in patients with RVH, although the difference from the other groups was not statistically significant. 
CLUBBING OF FINGER-NAILS In contrast to cyanosis, the duration of finger clubbing was much longer in some of the non-RVH cases than in those with RVH. Although a significant correlation was not demonstrated it seems that the development of finger clubbing does not indicate the onset of RVH.

RV HYPERTROPHY AND RV FAILURE The interval between clinical diagnosis of RVH and death and the duration of persistent right ventricular failure were determined from the clinical notes. Both conditions are difficult to diagnose in CF, the first because overinflation of the lungs makes palpation of the heart difficult, the second because fluid retention can be a feature of severe obstructive lung disease.

RVH was diagnosed in life in four of the 12 mild RVH cases, and in three of the 14 severe RVH cases. Terminal right ventricular failure was more frequently diagnosed-in two of the three neonates, in three of six non-RVH, seven of 12 mild RVH, and 11 of 14 severe RVH cases. The mean duration of failure was longest in the severe RVH cases and shortest in the non-RVH cases, although the difference did not reach statistical significance.

INFECTION WITH PSEUDOMONAS PYOCYANEA This organism is commonly found in the sputum of patients with severe cystic fibrosis (Lawson, 1969; Mearns, Hunt, and Rushworth, 1972). It had been isolated in all except the neonate and two infants, but no correlation was found between the duration of this infection and the presence or degree of RVH.

HEIGHT AND WEIGHT OF PATIENTS The children were underweight for their age. Their weights were all below the 25 th centile on the expected weight charts (Tanner, Whitehouse, and Takaishi, 1966), while most were at or below the 10th centile. The children were also shorter than expected. Most were between the 3rd and 25th centile values on the expected height charts, six were at the 50th centile value, and only one was at the 75th. Children with RVH were no more stunted than those without RVH.

ELECTROCARDIOGRAMS Electrocardiograms were recorded in 15 cases. A QRS frontal axis of more than $90^{\circ}$ (right axis deviation) was accepted as evidence of RVH. Right axis deviation was not seen in the three cases without RVH at necropsy.
Of the 12 cases with RVH at necropsy, seven had right axis deviation on the ECG. Thus the ECG did not detect some cases of RVH, but in 10 there was agreement between elecrocardiographic and pathological findings. No 'false' positives wer seen in that right axis deviation was always associo ated with RVH.

RADIOGRAPHIC STUDIES In 25 cases (those dying aged 6 years or more) 'heart diameter' and 'lung length' were measured (see Fig. 2) on the lask chest radiograph before death, using the technique described by Simon et al. (1972), and compare with the centile charts.

It will be seen that increase in heart diameter is a poor indicator of RVH. None of the mild RVI cases and only three of the severe $\mathrm{RVH}$ cases showed this change. Lung length correlates bettex with RVH. This measurement was below the 50t centile in all non-RVH cases, while only four of those with RVH had small lungs. Thus in 21 of 25 cases there was a correlation between RVH and lung length.

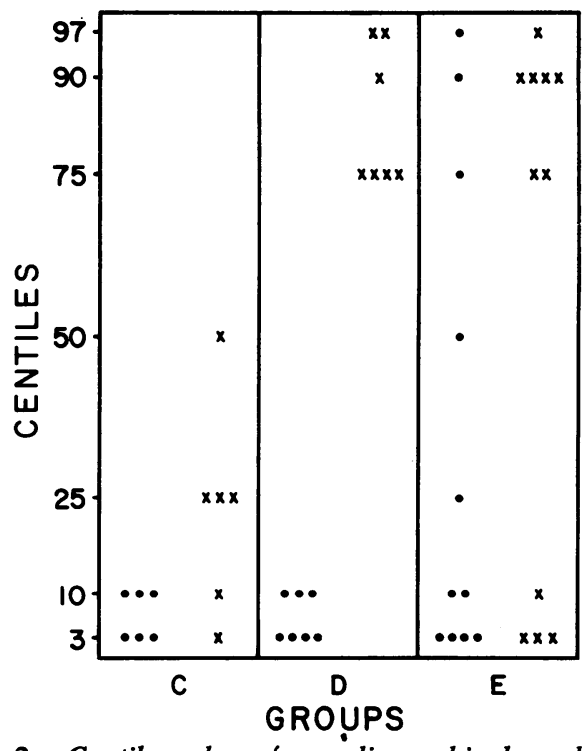

FIG. 2. Centile values for rádiographic lung lengt传 and heart diameter in the three older groups of children: $\bullet$ heart diameter; $X$ lung length.

\section{PATHOLOGICAL FINDINGS}

Lung volume before fixation varied widely bu政 tended to be smaller in non-RVH cases althouge no statistically significant correlation emerged. 
MACROSCOPIC POINT COUNTING Serious loss of peripheral lung tissue, that is, the alveolar region, henceforth referred to as 'parenchyma', was uncommon. The mean percentage of lung volume occupied by arteries was calculated for each of the five groups of patient. A significant correlation emerged between reduction in volume of arteries and the appearance of RVH $(P<0.05)$ (FIG. 3).

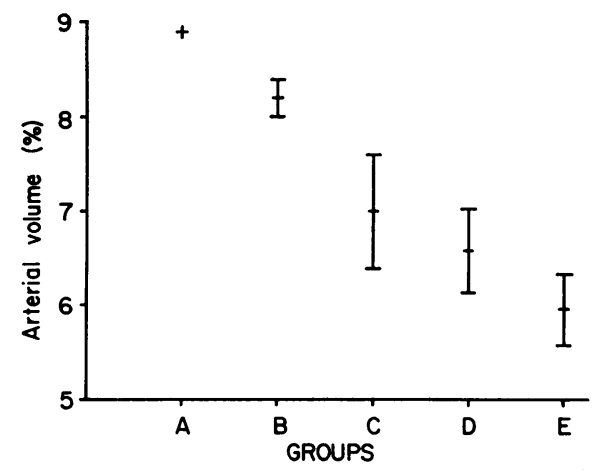

FIG. 3. CF patients-macroscopic arterial volume.

ARTERIAL DENSITY The number of arterial outlines of less than $500 \mu \mathrm{m}$ diameter was calculated per square millimetre fresh inflated lung. In each patient it varied greatly from one microscopic field to another, as did the mean values for each lobe.

The mean arterial density was calculated for each case from all counts, and a close correlation emerged between arterial reduction and degree of RVH. Figure 4 shows the mean values for the five patient groups. Thus macroscopic and microscopic analyses both reveal a correlation between RVH and a reduced pulmonary arterial tree. No such correlation was found with vein density.

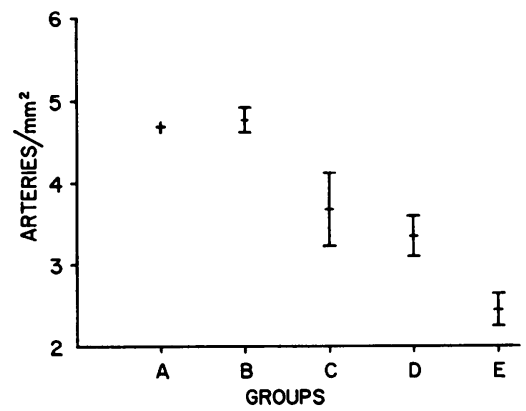

FIG. 4. CF patients-microscopic arteries per square millimetre.
ARTERIAL WALL THICKNESS The mean arterial wall thickness for vessels from $1000 \mu \mathrm{m}$ diameter down to $25 \mu \mathrm{m}$ grouped by size are shown for the three childhood groups (Fig. 5).

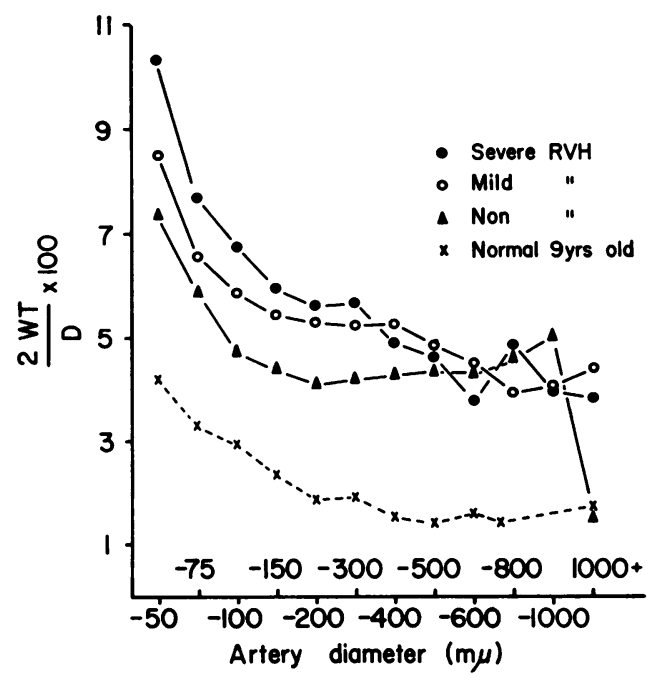

FIG. 5. CF patients-arterial wall thickness.

In the smaller arteries $(25-50 \mu \mathrm{m}$ and $50-75$ $\mu \mathrm{m})$ increasing wall thickness correlates significantly $(P<0.02)$ with the degree of RVH; although even in cases with no RVH, wall thickness is greater than normal (Elliott, 1964; Davies and Reid, 1970). When larger size ranges are considered the correlation is less close and, in arteries above $300 \mu \mathrm{m}$, fails to reach significance.

VEIN WALL THICKNESS Figure 6 shows the mean vein wall thickness for veins $25-50 \mu \mathrm{m}$ in diameter

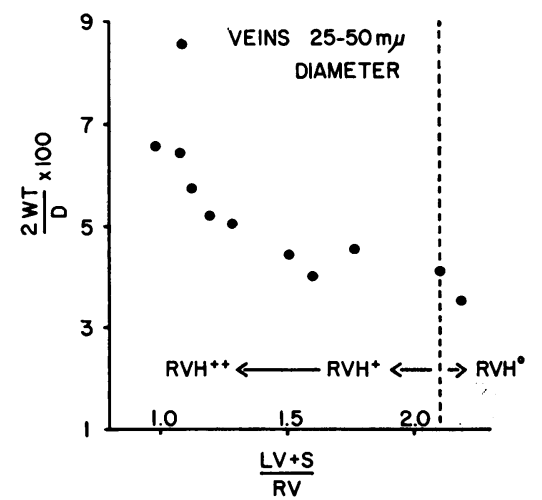

FIG. 6. Mean wall thickness of the smallest pulmonary veins in the 12 cases studied. 
in each of the 12 cases injected. In this smallest size range the correlation between wall thickness and $\mathrm{RVH}$ reaches significance of $\mathbf{P}<0.01$, that is, somewhat greater than that of arterial wall thickness and RVH. In larger veins the correlation becomes less significant and is not apparent above diameters of $200 \mu \mathrm{m}$.

POPULATION COUNTS As previously described, the size range in which the maximal concentration of partially muscular arteries occurs is the best indication of peripheral extension of muscle. Because muscle usually extends with age only groups $\mathrm{C}, \mathrm{D}$, and $\mathrm{E}$ can be compared with each other (Fig. 7). Peak partially muscular arterial concentrations are found in smaller size ranges when $\mathrm{RVH}$ is present, indicating peripheral extension of muscle.

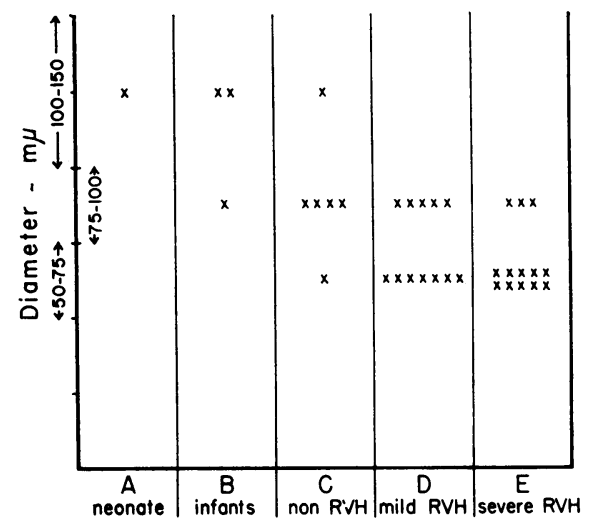

FIG. 7. Population count-size range of peak concentration of partially muscular arteries.

INTIMAL THICKENING AND SUBINTIMAL LONGITUDINAL MUSCLE Intimal changes were almost always found in severely affected areas of lung and were patchily distributed. A progressive increase in the mean number of blocks of lung tissue showing these changes was found in groups $C, D$, and $\mathrm{E}$ (Fig. 8) and is significant at the $P<0.02$ level.

\section{DISCUSSION}

It is striking that six of the 36 children in this series died from extensive lung disease without developing right ventricular hypertrophy although all had some degree of pulmonary artery muscle hypertrophy. This confirms the earlier report from our department that longstanding lung disease is not necessarily associated with $\mathrm{RVH}$ and that

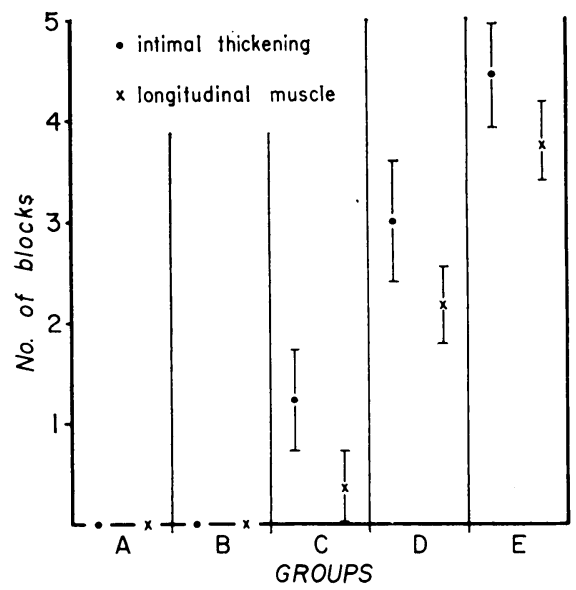

FIG. 8. Microscopic analysis-mean number blocks (out of 8) showing (1) intimal thickening, and (2) longitudinal muscle.

increased muscularity of the heart and pulmonary arteries do not necessarily go together (Davies, 1969).

The development of cardiac changes is noto directly related to age, there being no significanto difference in age at death between the non-RVH: mild $\mathrm{RVH}$, and severe $\mathrm{RVH}$ groups.

Clubbing of the finger-nails was reported, subject to errors of recording or observation, as present for a longer period in most of the non? RVH cases although this correlation did not reach significance. It is clear that clubbing does noe signify either a poor prognosis or the onset of RVH.

Right ventricular hypertrophy and failure were rarely recorded during life, perhaps because theo pulmonary signs overshadow the cardiac, and the alterations in circulating fluid volume make clini응 cal diagnosis of these conditions difficult.

It might seem that the relatively low haemo을. globin measurements in the CF children excludo polycythaemia but Caplan and Gross (1968) have demonstrated that for normal children values ares lower than for the adult. They reported a mearw haemoglobin level of $12.7 \mathrm{~g} / \mathrm{dl}$ in a group of $8 \mathbb{P}$ normal children aged 5-16 years, and somewhac higher levels in a similar age group of CF children but in the latter the haemoglobin levels did not rise to the same extent as the haematocrit because mean corpuscular haemoglobin concentration was reduced. Caplan and Gross (1968) also demon strated higher haemoglobin figures in CF patient 8 with arterial oxygen desaturation than in thos without. In our cases, severe RVH was associated 
with higher haemoglobin levels, apparently corroborating their findings. It is clear that polycythaemia in children with CF is less striking than in adult chronic bronchitics, where an increase in red cell number is associated with much higher levels of haemoglobin and of corpuscular haemoglobin concentration than in cystic fibrosis.

From all patients over the age of 1 year at death Pseudomonas pyocyanea had been cultured from the sputum, but in most cases other organisms, usually Staphylococcus aureus, were also found.

Of all the investigations carried out in this series of cystic fibrosis, increase in radiological estimation of 'lung length' seems to correlate best with the presence of RVH. This supports the necropsy finding that the lungs from $\mathrm{RVH}$ cases tend to be bulkier than those from non-RVH cases. It may be that the vessels of an undersized lung are incapable of developing the increased muscle necessarily associated with the development of RVH. This is the reverse of adult chronic bronchitis where it is the large lung of severe panacinar emphysema that lacks the arterial muscle and thus offers some 'protection' from RVH.

Electrocardiographic analysis seems as accurate in the detection of childhood as of adult RVH. Every patient showing right axis deviation on the ECG had an abnormally heavy right ventricle at necropsy but the ECG failed to detect five of the 12 cases with RVH. Thus ECG changes are good evidence of RVH, but their absence does not preclude its presence.

THE PULMONARY CIRCULATION The reduction of the arterial tree in CF could be the result of hypoplasia arising from the pulmonary disease. All the major pulmonary arterial branches (which develop in utero) were present but reduced in size, and more severely reduced when RVH was present. The smaller arteries which develop in post-natal life were reduced in number in all cases of CF. When RVH becomes more severe the reduction in arterial number becomes progressively more marked.

These changes were most apparent in the parts of the lung that were severely damaged and presumably hypoxic. Although wide variations were found in each lung, the overall arterial wall muscularity has, for the first time, been shown to correlate with the state of the right ventricle in CF. Increase in muscular wall thickness was found in all CF patients but was more marked in those with RVH. Although a statistically significant correlation was found between the two features, the variation between cases made it impossible to specify a wall thickness which separates 'RVH cases' from 'non-RVH cases'. This is probably due to the inherent difficulties of applying a sampling technique to lungs so patchily affected as in $\mathrm{CF}$.

The results suggest that increasing arterial wall thickness may at first be tolerated by the heart, but that RVH is induced when the thickness is increased beyond a certain point. The increase in arterial muscle is perhaps only one factor in the pathogenesis of RVH.

Peripheral extension of arterial muscle was demonstrated by population counts which showed that the peak concentration of partially muscular arteries occurred at smaller size ranges in cases with RVH than in those without. That peripheral extension did occur is also suggested by the similarity of the size distribution of the vessels compared with normal cases. If the $C F$ vessels were less distensible, apparent peripheral extension could be explained by 'larger' vessels with muscular walls not distending, but this would have reduced the numbers of vessels in the larger ranges, which was not observed.

In contrast to the arterial tree, no reduction was found in the volume of veins, nor in the number of small veins per unit area of lung. This may be the result of distance between vein and airway in the lung in contrast to the proximity of artery to airway. A bronchus plugged by mucus would, of necessity, produce considerable hypoxia in the wall of its accompanying artery. The veins, however, tend to run between the acini more or less equidistant from a number of bronchial pathways. In a patchily distributed disease such as CF the veins would be more uniformly affected than the arteries. Indeed, much greater variation in wall thickness was found in the arteries. This may be the reason for the closer correlation between vein wall thickness and RVH. It seems that in cystic fibrosis the arterial system either fails to develop completely, or else many small branches disappear as the disease progresses.

\section{REFERENCES}

Andersen, D. H. (1938). Cystic fibrosis of the pancreas and its relation to celiac disease; clinical and pathologic study. American Journal of Diseases of Childhood, 56, 344.

(1949). Therapy and prognosis of fibrocystic disease of the pancreas. Pediatrics, 3, 406.

Bowden, D. H. and Wyatt, J. P. (1963). Pathogenesis of cor pulmonale in cystic fibrosis (abstract). Circulation, 28, 693. 
Caplan, A. and Gross, S. (1968). Hematologic and serologic studies in cystic fibrosis. Journal of Pediatrics, 73, 540.

Davies, G. (1969). Lung damage, hypoplasia and right ventricular hypertrophy in cystic fibrosis. In Proceedings of the Fifth International Cystic Fibrosis Conference, edited by D. Lawson, p. 350. Cystic Fibrosis Research Trust, Stuart House, London.

- and Reid, L. (1970). The growth of the alveoli and pulmonary arteries in childhood. Thorax, 25, 669.

Dunnill, M. S. (1962). Quantitative methods in the study of pulmonary morphology. Thorax, 17, 320.

Elliott, F. M. (1964). The pulmonary artery system in normal and diseased lungs; structure in relation to pattern of branching. Ph.D. thesis, University of London.

Esterly, J. R. and Oppenheimer, E. H. (1968). Observations in cystic fibrosis of the pancreas. III. Pulmonary lesions. The Johns Hopkins Medical Journal, $122,94$.

Fulton, R. M., Hutchinson, E. C., and Jones, A. M. (1952). Ventricular weight in cardiac hypertrophy. British Heart Journal, 14, 413.

Goldring, R. M., Fishman, A. P., Turino, G. M., Cohen, H. I., Denning, C. R., and Andersen, D. H. (1964). Pulmonary hypertension and cor pulmonale in cystic fibrosis of the pancreas. Journal of Pediatrics, 65, 501 .

Hislop, A. (1971). The fetal and childhood development of the pulmonary circulation and its disturbance in certain types of congenital heart disease. Ph.D. thesis, University of London.

and Reid, L. (1970). New pathological findings in emphysema of childhood. I. Polyalveolar lobe with emphysema. Thorax, 25, 682.

Kelminson, L. L., Cotton, E. K., and Vogel, J. H. K. (1967). The reversibility of pulmonary hypertension in patients with cystic fibrosis. Observations on the effect of tolazoline hydrochloride. Pediatrics, 39, 24.

Lawson, D. (1969). Panel discussion on microbiology and chemotherapy of the respiratory tract in cystic fibrosis. Proceedings of the Fifth International Cystic Fibrosis Conference, edited by D. Lawson, p. 225. Cystic Fibrosis Research Trust, Stuart House, London.

May, C. D. and Lowe, C. U. (1949). Fibrosis of the pancreas in infants and children. An illustrated review of certain clinical features with special emphasis on the pulmonary and cardiac aspects. Journal of Pediatrics, 34, 663.

Mearns, M. B., Hunt, G. H., and Rushworth, R. (1972). Bacterial flora of the respiratory tract in patients with cystic fibrosis, 1950-1971. Archives of Diseases of Childhood, 47, 902.
Millard, F. J. C. (1965). The development and electrocardiographic diagnosis of right ventricular hyper- $\bar{O}$ trophy in chronic lung disease. M.D. thesis, $\frac{C}{\sigma}$ University of London.

Recavarren, S. and Arias-Stella, J. (1964). Growth and $\vec{D}$ development of the ventricular myocardium from $\triangle$ birth to adult life. British Heart Journal, 26, 187. ڤn

Royce, S. W. (1951). Cor pulmonale in infancy and $\overrightarrow{0}$ early childhood. Report on 34 patients with? special reference to the occurrence of pulmonary $\overrightarrow{\vec{\omega}}$ heart disease in cystic fibrosis of the pancreas. Pediatrics, 8, 255.

Schwachman, H. and Kulczycki, L. L. (1958). Longterm study of 105 patients with cystic fibrosis. Studies made over a five- to fourteen-year period. $\dot{\omega}$ American Journal of Diseases of Childhood, iv 96, 6.

Shinebourne, E. and Howarth, S. G. (1973). Congenital 음 heart disease with special reference to the first year of life. Medicine, No. 16, p. 999. Published by Medical Education (International) Ltd., $3 \sqsubseteq$ Fitzroy Square, London.

Siassi, B., Moss, A. J., and Dooley, R. R. (1971). $\overrightarrow{0}$ Clinical recognition of cor pulmonale in cystic $v$ fibrosis. Journal of Pediatrics, 78, 794.

Simon, G., Reid, L., Tanner, J. M., Goldstein, H., and Benjamin, B. (1972). Growth of radiologically determined heart diameter, lung width, and lung length from 5-19 years, with standards for clinicalo use. Archives of Diseases in Childhood, 47, 373.

Symchych, P. S. (1971). Pulmonary hypertension in cystic fibrosis. A descriptive and morphometric $\overline{\bar{O}}$ analysis of the pulmonary vasculature. Archives 3 of Pathology, 92, 409.

Tanner, J. M., Whitehouse, R. H., and Takaishi, M.0 (1966). Standards from birth to maturity for height, weight, height velocity, and weight velocity; British children, 1965. Part I. Archives of Diseases in Childhood, 14, 454.

Weibel, E. R. and Gomez, D. M. (1962). A principle $\frac{\sigma}{3}$ for counting tissue structures on random sections. Journal of Applied Physiology, 17, 343.

Wigglesworth, F. W. (1946). Fibrocystic disease of the pancreas. American Journal of Medical Science,o을 212, 351 .

World Health Organization (1961). Chronic Cor Pul=O monale. Technical Report Series No. 213, p. 6. WHO, Geneva.

Requests for reprints to: Professor Lynne Reid Department of Experimental Pathology, Cardiothoracic Institute, Brompton Hospital, London SW3:- 